\title{
The Reform of Teaching Method of Electronic Technology
}

\author{
Hou-Qin WEl ${ }^{1, a}$ and Zhong-Li WANG ${ }^{b^{*}}$
}

College of Electrical and Information Engineering, Beihua University, Jilin, China

a81231824@qq.com, b47198245@qq.com

*Corresponding author: Zhong-Li WANG

Keywords: reform and innovation; Interest; Heuristic teaching; teaching method

\begin{abstract}
The electronic technology develops rapidly with the development of economic technology. But the actual teaching of electronic technology lags far behind the pace of The Times, the content is old, the Traditional teaching methods cant not meet the need of the times. The urgent task is to reform. The focus is cultivating comprehensive and innovative talents as a teaching work.
\end{abstract}

\section{Introduction}

The curriculum of "electronic technology "is one of important basic course of electrical, the electron, the information, and so on. It has a strong practicality .He is not only closely related to daily life, but also plays a important role to other courses, includes the analog part and digital part, the content contains the basic working principle of the basic components and typical circuit, the goal is to make students master the basic working principle of the components and the analysis method of circuit . It is possible to make the student be calm in face of rapid development present situation, andin the future work and the further study has good ability of theoretical basis and support. Such as "High frequency electronic", and "communication Principle", "Single chip microcomputer "and other courses. But the Traditional teaching methods, the students is to be taught. Students were as instruments of passive to accept. Because of the difference of students' ability to learn, It is becomes boring more and more, teaching effect is bad, so teaching method must be reformed.

\section{The current situation of teaching}

\subsection{Traditional teaching methods is simple and old}

Traditional teaching methods are mainly cramming teaching in class, the knowledge is taught by the teachers, students were as instruments of passive to accept, and textbook which is lack of in Practicality and applicability cannot keep up with space. Students analysis and design of comprehensive ability is not strong for specific circuit .So they feel this course is boring. It is impossible to achieve the ideal result of teaching effect.

\subsection{The teaching arrangement is inappropriate}

Traditional teaching is pay more attention to theoretical teaching, practical teaching time is less. Firstly, though science and technology develop rapidly, practical teaching is just a few lines.Students who don't even understand the principle can connect circuit only according to the steps, complete the experiment. Practical and innovative experiment is lack, so students are in a passive position, are lack of enthusiasm, the experiment result is bad. Secondly, the disconnection between theory and practice causes students do not understand the significance of study this course,can not put learned knowledge into use. Thirdly, under the impact of the market economy,many students value practical ability and short-term profit point of view, are not interested in this kind of basic course, think that these courses are little use for future employment. Students pay more attention to the "single chip microcomputer", "C programming language", course , take these courses as the key of future employment, thus they cultivate themselves according to the cultivation of the vocational college students plan calls . They ignore the study of basic course, learning only for 
a test. Therefore, it is difficult thing to the students who want further study do not understand the theory of circuit and design the specific circuit.

\section{The reform of teaching method}

\subsection{Reform of teaching mode, arouse the students' enthusiasm}

Interest is the best teacher; the interest is mainly derived from the demand and curiosity. First of all, we have to let students feel the important role of people's life. My life can not leave the electronic device. Our family is filled with the refrigerator, TV; the car .We can't live without electronic products, like water is to fish. at the same time ,We should guide the students to analysis, to explore. Innovation. Let the students pay a leading role in study, fully arouse the enthusiasm of learning. In addition, the students can choose their interesting group on the electronic technology, every two people is one group, but each has a division of labor. Let the students of same group to analyze and design issues, determine the design program. At the same time, each student must also complete their specific design, such as computer aided design and simulation, after the installation and adjusting the scheme of hardware, the first software simulation, the design scheme is verified. Test, data access and design report finishing and summary. This will enable students to understand the every part of the design of the whole process, deepen understanding Logic functions, thus greatly reducing the hardware circuit debugging time.

\subsection{The traditional teaching method combined with modern teaching mode}

The development of computer technology and the Internet make multimedia technology has been widely applied to modern teaching, has become a kind of new type teaching methods. Multimedia technology contains the content such as pictures, music, and video, Can put the boring textbook knowledge to show more intuitive, vivid, image, In front of students, fully mobilize the enthusiasm of the students, inspire the students. The independent initiative of learning, Multimedia technology is using its abundant carrier, the curriculum, clear and concise introduction to the doubtful point, difficult point, at best. Based the effect of classroom teaching of electronic technology at the same time, also greatly the higher the efficiency of classroom teaching. For example, when we study the working principle of current carrier of the diode and triple tube, it is good helper.

\subsection{Talking about Teaching}

According to the content of each chapter and teaching objectives, the teachers can put forward some question, which requires students to use the knowledge learned to think about the answer, design several unknown problems. We step into new class with unknown problems, and look for these answers. At the same time, elicitation method of teaching can be used. We guide students to search, think, and solve the problems. Studying analog circuit analysis, different circuit analysis method is in a similar way to other circuit. The analysis method of basic amplifying circuit general from the static and dynamic analysis is also applicable to the differential amplifier circuit, to guide students to analyze the advantage of difference amplifier circuit.

\subsection{The combination of multimedia and EDA}

At present, multimedia technology has been widely used in teaching and learning, to provide a great convenience to teaching activities. However, the intelligent level of multimedia course is generally low in our country, The information content of the processing, transformation, conversion is still lack. For example, analyze the "analog circuit", in order to easy understanding and Learning with multimedia, teachers need to add and change the high-tech analog circuit, However, the current multimedia software cannot help teachers to achieve this.

Based on this, the effective combination of EDA software and multimedia software is needed. The basic course of electronic technology has some practical and operational. Through the teaching method, not only can improve students' practical ability, improve the quality of teaching, but also for the development of the community to build a solid talent backing. 


\section{The reform of practical teaching}

Teaching method the experimental training courses, student's choice by themselves according to their own ideas personally select experimental training topics, selection and combination of instruments and equipment, their certain experimental training methods and steps of data processing and analysis training results and experimental training, in a certain period of time using various means to design schematic diagram and assembly debugging, and finally come up with a complete product and reports. To stimulate students' interest in learning, and gradually to cultivate students' ability of using knowledge engineering practice. Experimental training teacher in addition to providing experiment training data, solve practical problems for the students to provide services, but also in the process of experimental training preparation, students learned according to the theory of knowledge and practice ability has been formed, the analysis summary of laboratory existing components, and according to the characteristics of each experiment practice and its sequence in the teaching, how it can be classified as the following four basic types: demonstration experiment training, validation experiments training practice, researching experiment, designing experiment training.

\subsection{Basic experiment teaching}

In the experiment of electrical and electronic technology, the basic experiment teaching occupies an important position. It is a process that students must go through. When teaching activities, we can use the way of independent experiment or affiliated experiment. The teaching content should focus on the basic knowledge to test the basic working principle ,the experimental design is too simple, students' learning and thinking are limited in the textbook, while learning experiment can not understand the purpose of the experiment teaching is very good, it is difficult to improve this should improve the independent thinking ability and practical operation ability..

\subsection{Comprehensive experimental teaching.}

In the design of electrical and electronic technology experiments, we can choose the knowledge of smart home, so that students can understand the important use of electrical and electronic technology in our smart home. Based on our smart home related electrical knowledge display by multimedia, let the students have a visual impression of the smart home, understand the real, thus breaking the previous closed teaching, improve the students' interest in electrical and electronic technology Students can choose which part of the interest, the content of this part of the analysis, design, simulation, welding,the simulation which is Protel ,Multisim ,EWB software is designed to verify the rationality of the design ,Only the circuit is completely rational, and then can welding circuit. students' level of electrical and electronic technology experiment meet to maximize learning.

\subsection{Innovative experimental teaching.}

In this teaching level, the teaching content should include analog electronic technology, circuit foundation and digital electronic technology and other aspects of the electronic professional knowledge. Students can independently solve some simple problems, coordination and cooperation to complete the system design, complete the design report and other related documents, the comprehensive ability of students is raised ,the comprehensive quality of students improve, training students to meet a certain innovation ability. For some top students, the school should organize the students to visit and participate in various competitions, provide a platform for the students to improve their own strength.

\subsection{0penness of electrical and electronic experimental teaching}

Open the experimental teaching of electronic technology for promoting, build an open platform for the electrical and electronic innovation experimental teaching. Openness of electrical and electronic experimental teaching means the students can operate experiment which do not need the teacher to prepare in advance, but need the student independent carried out in accordance with the specific requirements of circuit to design, and to formulate appropriate experimental plan , after the end of the experiment teaching to give students evaluation. Electrical and electronic technology experiment teachers should also be responsible for the part of the organization to study these spare capacity of 
students to take part in some activities or is a game, let the students to innovative ideas into practice, stimulate students' learning enthusiasm.

Finally, it is sure to make the open teaching has good effect, must meet the following conditions.Firstly, the students must have self-consciousness, only in this way can students completed on time with good quality, obtained the certain effect. Secondly, it wants to have a high quality teaching staff, so that can better help students to improve the quality of the training innovation ability in the process of experiment.Thirdly,it needs to find effective experimental method to simplify and optimize test management by computer or the Internet work,and ensure the safety of the experimental hardware.In the process of experiment, the students play a leading role; independently complete the experiment design and management experiment. Teachers only make macroeconomic regulation and control. The appraisal effect pays great attention to the practice process; pay more attention to students encounter difficulties in practice when dealing with the attitude of the problem and the team cooperation ability. Through the experiment, the students not only master the communication professional comprehensive knowledge, but also learn to calmly cope with setback ability and the team cooperation ability.

In a word, in the teaching reform experiment of electrical and electronic technology, electrical and electronic technology experiment teaching content should be according to the different levels of students and students of different major, while we should strengthen the introduction the relevant knowledge in the practical work, arouse students' interest . The school should also establish electrical and electronic technology experiment teaching level, optimize teaching content, improve the experimental teaching method, create experimental teaching platform open, cultivate students' interest for electrical and electronic technology experiment teaching, in order to exercise their own hands the actual operation ability, improve the ability to solve problems independently and cultivate innovation thinking.

\section{Means of achievement evaluation}

The traditional teaching the student evaluation system pays more attention to the theory courses than practice lesson. So the students is lack of learning enthusiasm.The important content of teaching reform, in accordance with the the needs of the teaching process, performance at ordinary times, compaction Practice ability, innovation ability, to establish and implement the process and ultimately result with the combination of diversified evaluation system. Each assessment of class is related to a completed knowledge .To Check the teaching effect, it needs a criterion to timely evaluate the situation of students' understand and master knowledge,adjust the teaching process, and coordination teachers teaching and students' learning.Only in this way, good teaching effect will be obtained.

\section{Conclusions}

Electronic technology is a practical course, it is necessary to Increase practice teaching time.It is only way to the improve in teaching contents, teaching methods, teaching means, to constantly collect students' feedback, repeat and improve the teaching mean, so it can fully arouse the enthusiasm of the students. But the development of electronic technology and network technology is very quick and constantly update, this requires that the teachers constantly study and learn new knowledge for teaching, By this way ,it can meet the need of development of times. This can fully initiative enthusiasm, cultivate students' Self-study ability, deepen the interaction between teachers and students link, active classroom atmosphere and create a good classroom atmosphere.

\section{References}

[1] Bo wang, Yan Zhang,Meiling Wang.The exploration of teaching reform of electronic technology course design[J]. The laboratory research and exploration,2013,10 (32):380-382. 
[2] Mei Li, Dongmei Zhao.Strengthen the practice teaching reform, improving the students' comprehensive quality [J]. Journal of laboratory research and exploration,2011,30 (6) : 261-263.

[3] Huaguang Kang. Electronic technology foundation[M].(Sixth Edition)BeiJing:Higher Education Press,2014.

[4] Zenghuang Qin. Electrotechnics[M].(Sixth Edition).BeiJing:Higher Education Press,2012.

[5] Xingwei,Yajie dong. The experimental teaching methods of electrical and electronic technology[J]. Forum science and technology,2014(2):146-147.

[6] Jian Chen.The reform of electronic technology foundation course teaching method[J].Era of agricultural machinery.2015,12(42):93-97.

[7] Zhe Xu.Introduction of teaching reform to electronic technology basic course[J] .Modern vocational education,2012(8):68-69.

[8] Jingcao Yu.Reform and practiceof electronic course teaching[J]. China's new communication,2012,10.

[9] Shi Hui.Thinking of electronic technology teaching reform[J].Computer knowledge and technology,2014(2):123-125.

[10]Qinghe Wang.Digital electronic technology to explore and reform the teaching[J]. The educational reform frontier,2015,2(12):213-215. 